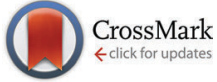

Cite this: Phys. Chem. Chem. Phys., 2016, 18, 15369

Received 11th February 2016 Accepted 10th May 2016

DOI: $10.1039 / c 6 c p 00948 d$

www.rsc.org/pccp

\title{
Why is a proton transformed into a hydride by [NiFe] hydrogenases? An intrinsic reactivity analysis based on conceptual DFT $\dagger$
}

\author{
Siyao Qiu, $\ddagger^{\mathrm{a}}$ Luis Miguel Azofra, $\ddagger^{\mathrm{ab}}$ Douglas R. MacFarlane*ab and Chenghua Sun $\star^{\mathrm{ab}}$ \\ The hydrogen evolution reaction (HER) catalysed by [NiFe] hydrogenases entails a series of chemical \\ events involving great mechanistic interest. In an attempt to understand and delve into the question \\ about 'Why does nature work in that way?', an in-depth intrinsic reactivity analysis based on conceptual \\ DFT has been carried out focusing on the so-called $\mathbf{I} \mathbf{1}$ to $\mathbf{N i}-\mathbf{C}$ step, i.e. our work tries to answer how \\ and why the proton attached to the reactive sulphur atom from one of the exo-cyclic cysteine residues \\ is transformed into a bridging hydride to be shared between the $\mathrm{Ni} / \mathrm{Fe}$ metals in the active site of [NiFe] \\ hydrogenases, which involves not only $\mathrm{H}$ migration, but also a change of the charge state on $\mathrm{Ni}$ from \\ $\mathrm{Ni}\left({ }_{1}\right)$ to $\mathrm{Ni}($ III). Our DFT results suggest that the transformation is motivated by spontaneous \\ rearrangements of the electron density, and stabilisation comes from the decrease of both electronic \\ activity and electrophilicity index from $\mathrm{Ni}$.
}

\section{Introduction}

Hydrogenases $^{1,2}$ are an extraordinary group of metal-containing enzymes specialised towards the reversible catalytic conversion of protons plus electrons into dihydrogen $\left(\mathrm{H}_{2}\right)$. The performance of catalysts in this simplest chemical reaction (eqn (1)) attracts much attention, not only due to its crucial importance in the understanding of the biochemistry of hydrogenases, but also because it can serve as the basis of the bio-inspired design of high-performance catalysts based on earth-abundant metals ${ }^{3,4}$ for the efficient production of $\mathrm{H}_{2}$-a promising environmentally friendly alternative to energy sources based on hydrocarbon compounds. 5

$$
2 \mathrm{H}^{+}+2 \mathrm{e}^{-} \rightarrow \mathrm{H}_{2}
$$

Focusing on the metal ions in the active site, hydrogenase enzymes can be classified into three main kinds: [NiFe], [FeFe], and [Fe]. However, only bimetallic [NiFe] and [FeFe] hydrogenases can catalyse the reversible $\mathrm{H}_{2}$ oxidation into protons plus electrons. [NiFe] hydrogenases also have better $\mathrm{O}_{2}$ tolerance

\footnotetext{
${ }^{a}$ School of Chemistry, Faculty of Science, Monash University, Clayton, VIC 3800, Australia. E-mail: Douglas.MacFarlane@monash.edu, Chenghua.Sun@monash.edu; Fax: +61 39905 4597; Tel: +61 399029916

${ }^{b}$ ARC Centre of Excellence for Electromaterials Science (ACES), School of Chemistry, Faculty of Science, Monash University, Clayton, VIC 3800, Australia

$\dagger$ Electronic supplementary information (ESI) available: Theoretical framework, analysis of other conceptual DFT properties, and Cartesian coordinates for the TS See DOI: $10.1039 / \mathrm{c} 6 \mathrm{cp} 00948 \mathrm{~d}$

\$ These authors have equally contributed to the development of this work.
}

than the $[\mathrm{FeFe}]$ ones. ${ }^{7}$ The active site of the $[\mathrm{NiFe}]$ hydrogenases is constituted by a bimetallic four-membered ring connecting the $\mathrm{Ni}$ and $\mathrm{Fe}$ metals through two sulphur atoms as part of two cysteine residues from the protein environment. ${ }^{8}$ Also, as exo-cyclic ligands, two cysteine residues are attached on the $\mathrm{Ni}$ metal, and three inorganic ligands are linked to Fe composing the $\left[\mathrm{Fe}(\mathrm{CN})_{2}(\mathrm{CO})\right]$ moiety.

Several studies, both theoretical and experimental, have been carried out in the recent decades with the aim to deepen the understanding of the hydrogen evolution reaction (HER) mechanism followed by [NiFe] hydrogenases. Those involving structural characterisation $^{9-30}$ and investigations of the metal multiplicities $^{31-35}$ deserve special mention, having generated extensive and rich literature. The study of the enzymatic activity of [NiFe] hydrogenases which turn to inactive states when placed under aerobic conditions deserves special mention: by the presence of the $\mathrm{OOH}^{-}$and $\mathrm{OH}^{-}$species interacting at the active site, a blocking of the bi-metallic site prevents the HER, the $[\mathrm{NiFe}]$ hydrogenases being reactivated once under a $\mathrm{H}_{2}$ atmosphere. ${ }^{14,15,18,22}$

From an overall point of view, the active site of [NiFe] hydrogenases in their oxidised active state, Ni-SI Scheme 1), acts as the site for the injection of one $\mathrm{H}^{+} / \mathrm{e}^{-}$pair. The so-called I1 state is postulated as an intermediate structure ${ }^{17}$ during which the $\mathrm{H}^{+}$ion is placed on the reactive sulphur atom from one of the exo-cyclic cysteine residues; the electron goes to $\mathrm{Ni}$, modifying its charge state by a reduction from $\mathrm{Ni}(\mathrm{II})$ to $\mathrm{Ni}(\mathrm{I})$. Subsequently, $\mathrm{Ni}(\mathrm{I})$ is re-oxidised, losing $2 \mathrm{e}^{-}$to transform $\mathrm{H}^{+}$ into hydride forming $\mathrm{Ni}(\mathrm{III})$ in the Ni-C state, as suggested by 


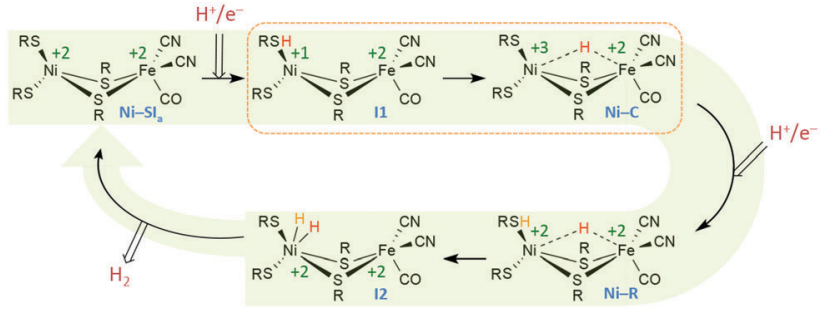

Scheme 1 Hydrogen evolution reaction (HER) path followed by [NiFe] hydrogenases.

Siegbahn in $2004 .{ }^{36}$ The objective of the present work is to provide further insights into this crucial step.

As a second step along the HER path, another $\mathrm{H}^{+} / \mathrm{e}^{-}$pair is collected by the Ni-R species. In similarity with $\mathbf{I 1}, \mathbf{I} 2$ is postulated as an intermediate structure in which $\mathrm{H}_{2}$ is produced and sequestrated by the Ni centre, to be finally released. The active site is thereby returned to the original $\mathbf{~ N i - S I} \mathbf{a}_{\mathbf{a}}$ configuration. Recent investigations by our group corroborate that the minimum energy path for the HER in [NiFe] hydrogenases follows a singlet multiplicity route. ${ }^{37}$

\section{Computational details}

Thus the geometries of the minima and the transition state (TS) for the proton transformation into hydride catalysed by the active site of [NiFe] hydrogenases (the so-called I1 to Ni-C step) have been fully optimised through the use of density functional theory (DFT) via the spin-unrestricted Kohn-Sham (UKS) formalism and the BP86 functional. ${ }^{38,39}$ Two-layered-integrated basis sets through the ONIOM approach ${ }^{40}$ have been applied, using the Def2TZVPP effective core potential for the active site (constituted by the metal, sulphur, and ligands attached to the Fe atoms), and the smaller Def2SVP effective core potential for the carbon chains directly bound to sulphur atoms. ${ }^{41}$ In all cases, the EDIIS/CDIIS procedure was applied for the selfconsistent field (SCF) convergence. ${ }^{42}$ The synchronous transitguided quasi-Newton (STQN) ${ }^{43}$ method (QST3) has been used to locate the TS, having checked that no spin contamination occurs during the breaking and formation of bond events in the TS. With the aim to confirm that the located TS connects reactants and products and in order to describe the intermediate structures along the minimum energy path, the intrinsic reaction coordinate (IRC) procedure, in which the reaction coordinate, $\xi$, is expressed in mass-weighted internal coordinates, ${ }^{44}$ has been employed using a step-size equal to 0.05 bohr. During the IRC calculation, a tight criterion was imposed for convergence and the force constants were computed through the improved CalcFC algorithm. In all cases, frequency calculations were performed in order to confirm the nature of the stationary points (minima or first-order TS with one imaginary frequency). All calculations were carried out using the facilities provided by the Gaussian 09 package (revision D.01). ${ }^{45}$

According to previous studies, the DFT modelling of [NiFe] hydrogenases exhibits a smaller unsigned error in describing the enzymatic structure when using the BP86 functional. Also, the effect of the basis set has only a minor role. Thus, the selection of the level of theory in the present work is not only justified by this, but also offers results comparable with ab initio coupled-cluster CCSD calculations that, contrary to what is observed when using B3LYP, show an energy preference

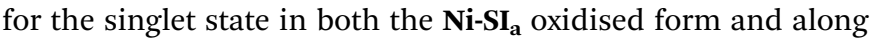
the entire path for the HER. ${ }^{35}$

The model used in the present study has been built on the basis of the X-ray crystallographic structure of the reduced [NiFe] hydrogenase from Desulfovibrio vulgaris str. 'Miyazaki F' organism (PDB accession code $1 \mathrm{H} 2 \mathrm{R})^{46}$ provided by Higuchi et $a l^{47}$ In this regard, in order to keep the same structurereactivity pattern as in the original enzyme, the distal carbon atoms were frozen during optimisation and IRC calculations.

Finally, since natural bond orbital $(\mathrm{NBO})^{48}$ methodology provides reliable estimations of the electronic population, the NBO6.0 program ${ }^{49}$ has been employed for such a purpose on the atomic centres.

\section{Results and discussion}

Conceptual DFT ${ }^{50}$ (CDFT) offers a range of useful theoretical tools allowing an analysis of the intrinsic reactivity for the chemical events occurring at the electronic level, which are directly associated with the physicochemical properties of both global and local nature. When the energy of the process is represented along the intrinsic reaction coordinate (IRC $=\xi),{ }^{51}$ three main points can be located: reactants $\left(\xi_{\mathrm{R}}\right.$, most negative value of $\xi$ ), transition state $\left(\xi_{\mathrm{TS}}=0 \mathrm{amu}^{1 / 2}\right.$ bohr, by definition), and products $\left(\xi_{\mathrm{P}}\right.$, most positive value of $\left.\xi\right)$. In the case at hand, the activation energy for the reaction involving the proton transformation into hydride catalysed by [NiFe] hydrogenases, $E^{\ddagger}=E\left(\xi_{\mathrm{TS}}\right)-E\left(\xi_{\mathrm{R}}\right)$, shows a value of $7.6 \mathrm{kcal} \mathrm{mol}^{-1}$ (see Fig. 1, left), while the reaction energy, $E_{\mathrm{R}}=E\left(\xi_{\mathrm{P}}\right)-E\left(\xi_{\mathrm{R}}\right)$, is equal to $-13.2 \mathrm{kcal} \mathrm{mol}^{-1}$. Calculations at the same computational level indicate a value of Gibbs free reaction energy at room temperature equal to $-12.0 \mathrm{kcal} \mathrm{mol}^{-1}$, as proof of the spontaneity of this process under mild conditions. ${ }^{37}$

Similarly, the representation of the reaction force $F v s$. the IRC $(F$ is defined as the negative first derivative of the energy with respect to $\xi$, eqn (2)) pinpoints the existence of one minimum between $\left[\xi_{\mathrm{R}}, \xi_{\mathrm{TS}}\right]$ and one maximum between $\left[\xi_{\mathrm{TS}}, \xi_{\mathrm{P}}\right]$, corresponding to the so-called $\xi_{1}$ and $\xi_{2}$ values on the reaction coordinate.

$$
F(\xi)=-\mathrm{d} E / \mathrm{d} \xi
$$

This simple tool has a great significance from a mechanistic point of view, since the areas between the $\left[\xi_{\mathrm{R}}, \xi_{1}\right]$, $\left[\xi_{1}, \xi_{2}\right]$, and $\left[\xi_{2}, \xi_{\mathrm{P}}\right]$ ranges are considered as the regions associated with reactants (R), transition state (TS), and products (P), respectively.

As indicated in the theoretical framework (see ESI $\dagger$ ), the activation energy of a reaction can be split into two quantities, $W_{1}$ and $W_{2}($ eqn (3)):

$$
E^{\ddagger}=W_{1}+W_{2}
$$



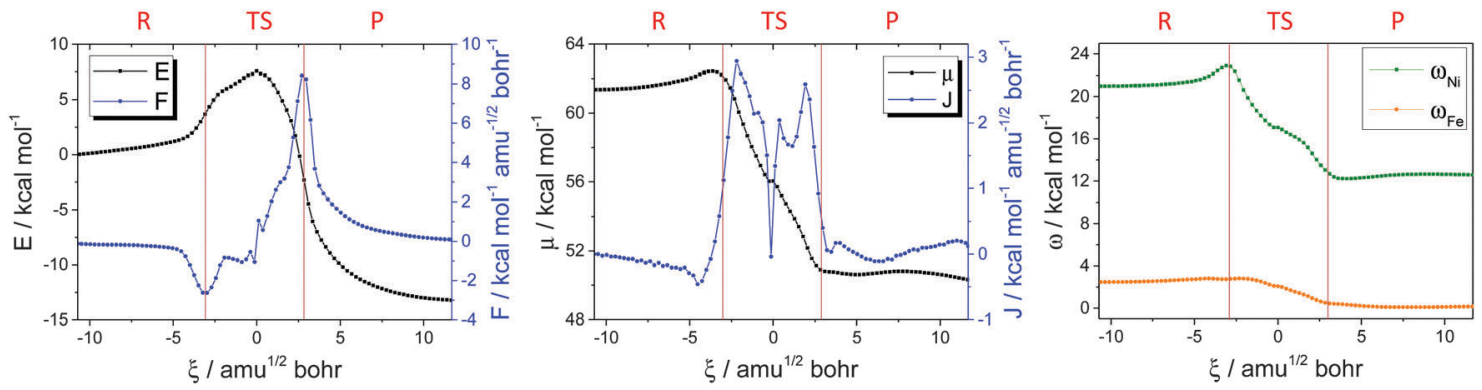

Fig. 1 Left, energy (in kcal mol ${ }^{-1}$, black) and reaction force (in kcal mol ${ }^{-1} \mathrm{amu}^{-1 / 2} \mathrm{bohr}^{-1}$, blue) profiles; centre, electronic chemical potential (in kcal mol ${ }^{-1}$, black) and reaction electronic flux (in kcal mol ${ }^{-1} \mathrm{amu}^{-1 / 2} \mathrm{bohr}^{-1}$, blue) profiles; and right, local electrophilicity index profiles (in kcal mol ${ }^{-1}$ ) for $\mathrm{Ni}_{\text {(green) }}$ and Fe (orange) atoms vs. the IRC (in amu $u^{1 / 2}$ bohr). Note: $\Delta \xi=0.26 \mathrm{amu}^{1 / 2}$ bohr has been selected for clarity in the chart representations.

As stated by Politzer and co-workers, ${ }^{52}$ and nestled between the $\xi_{1}$ and $\xi_{\mathrm{R}}$ IRC positions (initial stage of the reaction at the $\mathrm{R}$ area and up to reach the TS zone), $W_{1}=E\left(\xi_{1}\right)-E\left(\xi_{\mathrm{R}}\right)$ can be related to the amount of energy required for the system to be reorganised geometrically, i.e. mainly due to structural reordering as a consequence of, for example, bond elongation/ shortening, angle bending, or rotational events. Such structural modifications prepare the system to start with the formal reactive process in this early stage of the reaction, and once entering the TS area, bond breaking and formation starts to occur. In this regard, $W_{2}=E\left(\xi_{\mathrm{TS}}\right)-E\left(\xi_{1}\right)$ can be related to the amount of energy demanded for the system for an electronic reorganisation in order to reach the TS, i.e. mainly electronic rearrangement along the aforementioned bond breaking/formation events.

In contradistinction to ideal-behaviour reaction force profiles, ${ }^{53}$ for the proton transformation into hydride catalysed by [NiFe] hydrogenases (see Fig. 1, left) it can be seen that once the system passes beyond the reactant zone $\left(\xi_{1}=-2.97 \mathrm{amu}^{1 / 2} \mathrm{bohr}\right)$, the slope of $F$ increases. The expected behaviour establishes that this trend should be constant along the TS area and up to the product region; however in the range $\xi \in[-1.80,-0.89] \mathrm{amu}^{1 / 2}$ bohr, the slope of $F$ returns to negative.

Precisely based on the above concepts, this information can reveal that after the geometrical reorganisation up to $\xi_{1}$, a certain amount of energy is spent on the first electron transfer from $\mathrm{Ni}(\mathrm{I})$ to $\mathrm{H}^{+}$, to form $\mathrm{Ni}(\mathrm{II})$ and $\mathrm{H}^{\bullet}$. Subsequently, the system is required to be structurally reorganised along the range $\xi \in[-1.80,-0.89] \mathrm{amu}^{1 / 2}$ bohr, to be prepared for the second electron transfer to form $\mathrm{Ni}(\mathrm{III})$ and hydride $\left(\mathrm{H}^{-}{ }^{-}\right)$. According to the reaction force profile, this second transfer is produced before the TS is reached. Otherwise, a change in the slope of $F$ should occur between $\xi_{\mathrm{TS}}$ and $\xi_{2}$. Similar trends in the reaction force have been recently described by Toro-Labbé and co-workers in the study of the carbocationic triple shift rearrangement, ${ }^{54}$ in which elementary reactions constituted by the classical R, TS, and $\mathrm{P}$ stationary points display atypical $F$ profiles with the appearance of more than two critical points. According to their interpretations, this results in the co-existence of primary (bond breaking and forming processes) and secondary (weakening and strengthening processes) events that occur asynchronously although in a concerted way.
Quantitatively of the $7.6 \mathrm{kcal} \mathrm{mol}{ }^{-1}$ demanded as the activation barrier, the first geometrical reorganisation requires $53 \%$ of this, followed by $26 \%$ associated with the first electron transfer, and $11 \%$ and $10 \%$ are used for the second geo-metrical reorganisation and second electron transfer, respectively.

The mechanistic information derived from the energy and the reaction force profiles is supplemented with the analysis of the electronic chemical potential, $\mu$, and its negative first derivative with respect to $\xi$, the so-called reaction electronic flux (REF), $J$. (eqn (4) and (5)). In this regard, the application of finite differences and Koopmans' theorem ${ }^{55}$ by extension of the Hartree-Fock theory can approximate $\mu$ as the semi-sum of the energy for the lowest-unoccupied and highest-occupied frontier orbitals, LUMO $\left(\varepsilon_{\mathrm{L}}\right)$ and HOMO $\left(\varepsilon_{\mathrm{H}}\right)$, respectively, corresponding to the $\beta$ and $\alpha$ lowest-unoccupied and highest-occupied electrons in the case of the paramagnetic (spin doublet state) I1 and Ni-C forms of our [NiFe] hydrogenase model, in each case.

$$
\begin{aligned}
& \mu=\left(\varepsilon_{\mathrm{L}}+\varepsilon_{\mathrm{H}}\right) / 2 \\
& J(\xi)=-\mathrm{d} \mu / \mathrm{d} \xi
\end{aligned}
$$

Fig. 1 (centre) shows that the electronic activity measured by $\mu$ remains practically unchanged during the reactant and product stages. Thus, the main change in electronic activity takes place in the TS region with an important decrease by almost $11.5 \mathrm{kcal} \mathrm{mol}^{-1}$. On the basis that the larger the electronic activity the higher the reactivity, we can conclude that a decrease in former leads to a more stable state of such a system.

While from $\xi_{\mathrm{R}}$ to $\xi_{1}$ the proton attached on $\mathrm{S}$ simply experiences a rotation in order to be physically close to the $\mathrm{Ni}$ (see Fig. 2), from $\xi_{1}$ to reach the TS, the proton undergoes reduction by two electron transfers provided by Ni. This process, which involves the formation of an angularly stressed threemembered $\mathrm{Ni}-{ }^{*} \mathrm{H}-\mathrm{S}$ ring in the TS, is characterised by spontaneous rearrangements of the electron density, indicated by positive values of REF. The REF profile also exhibits some fluctuations coinciding with the changes previously observed in the reaction force profile, despite both properties having a different nature. This supports our hypothesis for the two electron transfers, which do not occur simultaneously but rather in two distinct and non-synchronous stages. Ultimately, the REF displays a small activity slightly displaced from the zero-flux regime at 
REACTANTS ZONE

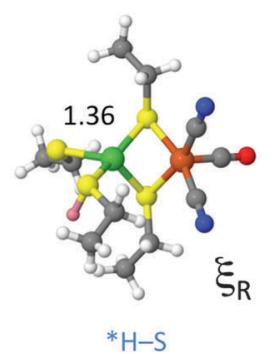

TRANSITION STATE ZONE
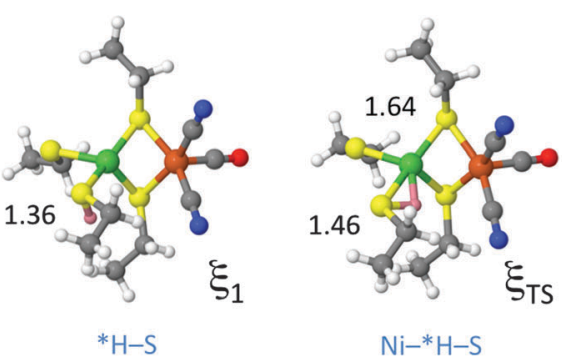

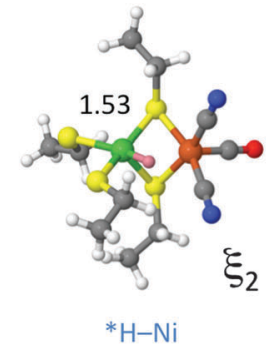

PRODUCTS ZONE

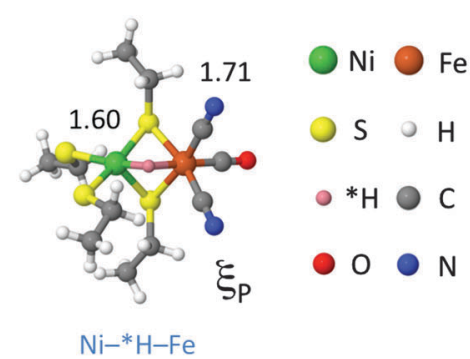

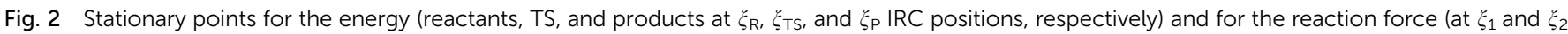

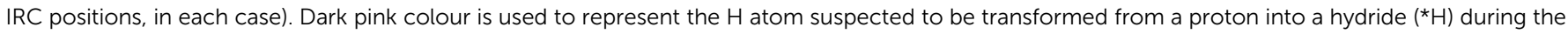
reaction path. Selected ${ }^{*} \mathrm{H}-\mathrm{X}(\mathrm{X}=\mathrm{S}, \mathrm{Ni}, \mathrm{Fe})$ distances are shown in $\AA$.

the beginning of the product area, which may be due to the incipient hydride-Fe bond formation.

While the analysis of the global properties provides a more general but enlightening insight into the chemical events taking place along the IRC, it is in the estimation of the local properties where a fully conclusive evaluation can be made. Here, the electrophilicity index (see Theoretical framework at ESI $\dagger$ ) is profiled as an approach to analysis in the attempt to explain 'what happens' with the added $\mathrm{H}$ along the $\mathbf{I 1}$ to Ni-C states on [NiFe] hydrogenases.

As indicated in Fig. 1 (right), the electrophilicity index of $\mathrm{Ni}$ $\left(\omega_{\mathrm{Ni}}\right)$ increases from $21.0 \mathrm{kcal} \mathrm{mol}^{-1}$ at I1 $\left(\xi_{\mathrm{R}}\right)$ to $22.7 \mathrm{kcal} \mathrm{mol}^{-1}$ at $\xi_{1}$, which is consistent with the idea that one electrophile (positively charged $\mathrm{Ni}$ ) increases its electrophilic behaviour as another electrophile $\left(\mathrm{H}^{+}\right)$comes closer. Previously, it was demonstrated that $\xi_{1}$ represents the moment from which the proton starts its transformation into hydride, turning the $\mathrm{Ni}$ into a more electrophilic centre, $\mathrm{Ni}(\mathrm{III})$, and converting $\mathrm{H}^{+}$into hydride prior to passing from the $\mathrm{H}^{\bullet}$, a highly nucleophilic species. The consequence of this process is the stabilisation of the system by the occurrence of a Lewis acid-base neutralisation, or from a kinetic perspective, by the occurrence of an electrophile-nucleophile neutralisation, leading to a decrease of $\omega_{\mathrm{Ni}}$ to $11.4 \mathrm{kcal} \mathrm{mol}^{-1}$.

As additional and fully conclusive evidence about the double-electron cession from $\mathrm{Ni}$ to $\mathrm{H}, \mathrm{NBO}$ contributions for the $\mathrm{Ni-}{ }^{*} \mathrm{H}$ and $\mathrm{Fe}-{ }^{*} \mathrm{H}$ bonds in the $\mathbf{N i - C}$ state reveal the existence of strongly binding interactions such as covalent forces. Specifically, the converted hydride establishes strong $\mathrm{H}_{\mathrm{lp}} \rightarrow$ $\sigma^{*}(\mathrm{NiS})$ and $\mathrm{H}_{\mathrm{lp}} \rightarrow \sigma^{*}(\mathrm{FeC})$ interactions with $E^{(2)}$ values of 68.8 and $66.1 \mathrm{kcal} \mathrm{mol}^{-1}$, that is, the hydride moiety has a similar behaviour as the $\mathrm{H}$ atoms connecting diborane via dihydrogen bonds. Finally and more importantly, very high occupancies of 0.53 e $\left(\mathrm{H}_{\mathrm{lp}}\right)$ with respective cessions of 0.29 and 0.23 e for the $\sigma^{*}(\mathrm{NiS})$ and $\sigma^{*}(\mathrm{FeC})$ orbitals can be seen (see Fig. 3).

However, what we can expect for the electrophilicity index of other 'protagonist' centres like Fe? The evolution of $\omega_{\mathrm{Fe}}$ along the IRC illustrates the minor role of this atom as an electrophilic centre. A small value of around $2.4 \mathrm{kcal} \mathrm{mol}^{-1}$ at I1 $\left(\xi_{\mathrm{R}}\right)$ can be seen, which is in accordance with the negative NBO
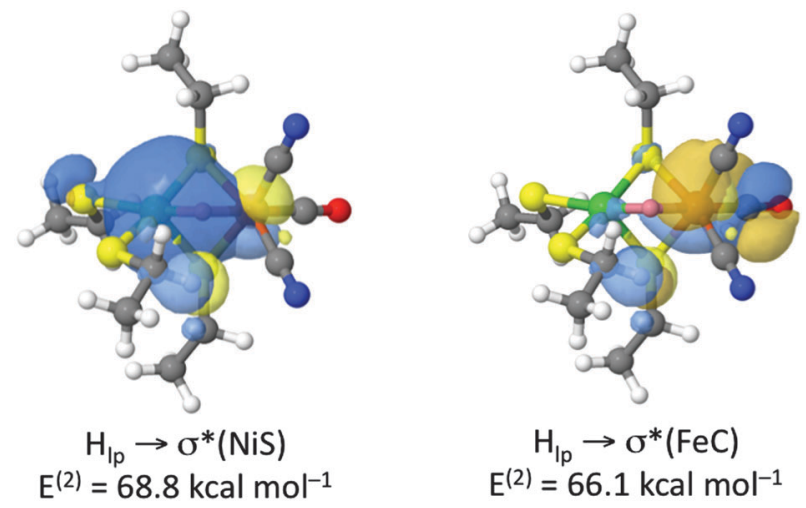

Fig. 3 Main NBO contributions to the $\mathrm{Ni}-{ }^{*} \mathrm{H}$ and $\mathrm{Fe}-{ }^{*} \mathrm{H}$ bonds for the Ni-C state.

atomic charge of $\mathrm{Fe}$ (see Fig. 4) due to the strong $\mathrm{CN}^{-}$donor ligands attached to it. How can the change in $q(\mathrm{Fe})$ to more negative values along the IRC path be interpreted? To answer this, it should be taken into account that the Fe centre acts as

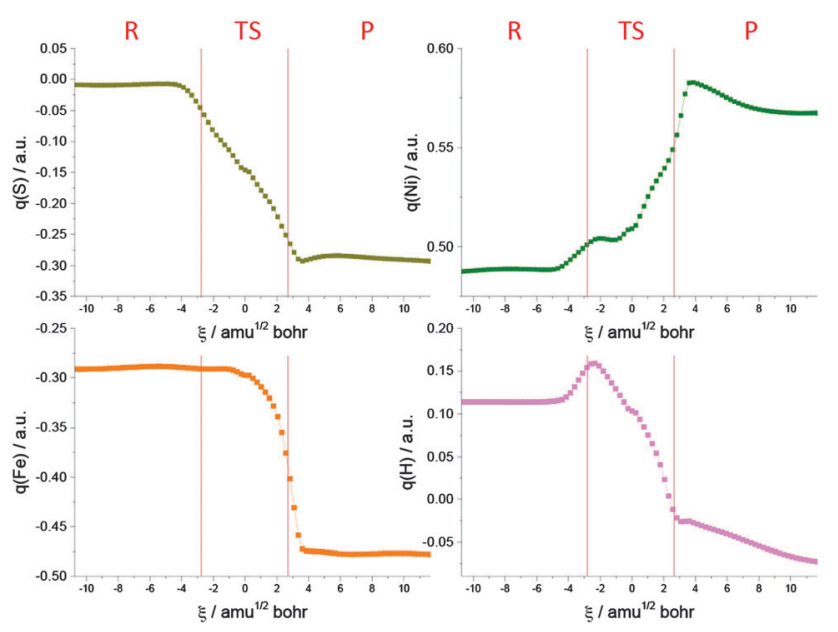

Fig. 4 NBO atomic charge evolution (in a.u.) for the reactive S (olive), $\mathrm{Ni}$ (green), Fe (orange), and reactive $\mathrm{H}$ (lilac) atoms along the IRC (in $\mathrm{amu}^{1 / 2}$ bohr). Note: for clarity, chart representations only contain a few representative IRC points; however, the $q$ analysis has been done using the full data. 
an acceptor moiety that also retains the $\mathrm{H}$ atom once converted into hydride. This is especially evident just before $\xi_{2}$, i.e. once the converted hydride starts to interact with Fe.

Monitoring the NBO atomic charge, $q$, along the IRC also indicates that the main changes are located in the TS area (see Fig. 4). On the one hand, $q(\mathrm{Ni})$ increases to more positive values as a result of loss/transfer of electrons. The opposite is exhibited by $q(\mathrm{~S})$, in which the loss of the proton leads to a more negative atomic charge. The NBO charge associated with the $\mathrm{H}$ moiety shows a similar behaviour to $\omega_{\mathrm{Ni}}$. Whilst at the beginning of the reaction $q(\mathrm{H})$ has a value close to 0.10 a.u., at the end of the reaction, i.e. once hydride is formed, the charge is negative $(-0.08$ a.u.), corroborating the hydride character of this species.

\section{Conclusions}

In summary, the I1 to Ni-C step for the HER mechanism in [NiFe] hydrogenases is characterised by the transformation of $\mathrm{H}^{+}$into a bridging hydride between the Ni and Fe centres. Two electrons are needed for such a transformation, provided by oxidation of $\mathrm{Ni}(\mathrm{I})$ to $\mathrm{Ni}(\mathrm{III})$. The transfer of these two electrons does not occur simultaneously but occurs in two non-synchronous stages, as hypothesised by the reaction force along the IRC, among other properties. Our conceptual DFT results suggest that such a transformation is motivated by spontaneous rearrangements of the electron density. Also, stabilisation from the decrease of electronic activity and electrophilicity index from $\mathrm{Ni}$ results in the occurrence of a Lewis acid-base neutralisation, or from a kinetic perspective, in the occurrence of an electrophilenucleophile neutralisation. Finally, the transformation of the proton into hydride exhibits a spontaneous value of the reaction Gibbs free energy at room temperature. Finally, the information provided here may also be of help for the design of bio-inspired catalysts for hydrogen production.

\section{Acknowledgements}

The authors acknowledge the Australian Research Council (ARC) for its support through the Australian Centre for Electromaterials Science (ACES), Discover Project (CS, DP130100268), Future Fellowship (CS, FT130100076) and Australian Laureate Fellowship (DRM) schemes. The National Computational Infrastructure (NCI), which is supported by the Australian Government, and the Monash eResearch Centre and eSolutions-Research Support Services through the use of the Monash Campus HPC Cluster are also acknowledged for providing the computational resources. Gratitude is also due to Prof. Dr Ibon Alkorta (IQM-CSIC) for his valuable advice.

\section{Notes and references}

1 P. M. Vignais and B. Billoud, Chem. Rev., 2007, 107, 4206-4272. 2 W. Lubitz, H. Ogata, O. Rüdiger and E. Reijerse, Chem. Rev., 2014, 114, 4081-4148.
3 J. K. Nørskov, T. Bligaard, A. Logadottir, J. R. Kitchin, J. G. Chen, S. Pandelov and U. Stimming, J. Electrochem. Soc., 2005, 152, J23-J26.

4 M. Wang, L. Chen and L. Sun, Energy Environ. Sci., 2012, 5, 6763.

5 N. Armaroli and V. Balzani, Angew. Chem., Int. Ed., 2007, 46, 52-66.

6 T. R. Cook, D. K. Dogutan, S. Y. Reece, Y. Surendranath, T. S. Teets and D. G. Nocera, Chem. Rev., 2010, 110, 6474-6502.

7 T. Burgdorf, O. Lenz, T. Buhrke, E. van der Linden, A. K. Jones, S. P. J. Albracht and B. Friedrich, J. Mol. Microbiol. Biotechnol., 2005, 10, 181-196.

8 E. Garcin, X. Vernede, E. C. Hatchikian, A. Volbeda, M. Frey and J. C. Fontecilla-Camps, Structure, 1999, 7, 557-566.

9 B. Bleijlevens, B. Faber and S. Albracht, JBIC, J. Biol. Inorg. Chem., 2001, 6, 763-769.

10 S. Li and M. B. Hall, Inorg. Chem., 2001, 40, 18-24.

11 S. Foerster, M. Stein, M. Brecht, H. Ogata, Y. Higuchi and W. Lubitz, J. Am. Chem. Soc., 2003, 125, 83-93.

12 A. De Lacey, A. Pardo, V. Fernández, S. Dementin, G. Adryanczyk-Perrier, E. C. Hatchikian and M. Rousset, JBIC, J. Biol. Inorg. Chem., 2004, 9, 636-642.

13 S. Foerster, M. Gastel, M. Brecht and W. Lubitz, JBIC, J. Biol. Inorg. Chem., 2005, 10, 51-62.

14 H. Ogata, S. Hirota, A. Nakahara, H. Komori, N. Shibata, T. Kato, K. Kano and Y. Higuchi, Structure, 2005, 13, 1635-1642.

15 A. Volbeda, L. Martin, C. Cavazza, M. Matho, B. Faber, W. Roseboom, S. J. Albracht, E. Garcin, M. Rousset and J. Fontecilla-Camps, JBIC, J. Biol. Inorg. Chem., 2005, 10, 239-249.

16 C. Fichtner, C. Laurich, E. Bothe and W. Lubitz, Biochemistry, 2006, 45, 9706-9716.

17 A. Pardo, A. De Lacey, V. Fernández, H.-J. Fan, Y. Fan and M. Hall, JBIC, J. Biol. Inorg. Chem., 2006, 11, 286-306.

18 M. van Gastel, M. Stein, M. Brecht, O. Schröder, F. Lendzian, R. Bittl, H. Ogata, Y. Higuchi and W. Lubitz, JBIC, J. Biol. Inorg. Chem., 2006, 11, 41-51.

19 A. L. De Lacey, V. M. Fernández, M. Rousset and R. Cammack, Chem. Rev., 2007, 107, 4304-4330.

20 J. C. Fontecilla-Camps, A. Volbeda, C. Cavazza and Y. Nicolet, Chem. Rev., 2007, 107, 4273-4303.

21 W. Lubitz, E. Reijerse and M. van Gastel, Chem. Rev., 2007, 107, 4331-4365.

22 A. Pardo, A. De Lacey, V. Fernández, Y. Fan and M. Hall, JBIC, J. Biol. Inorg. Chem., 2007, 12, 751-760.

23 P. E. M. Siegbahn, C. R. Chim., 2007, 10, 766-774.

24 H. Wu and M. B. Hall, C. R. Chim., 2008, 11, 790-804.

25 M.-E. Pandelia, H. Ogata, L. J. Currell, M. Flores and W. Lubitz, Biochim. Biophys. Acta, 2010, 1797, 304-313.

26 M. Kampa, W. Lubitz, M. van Gastel and F. Neese, JBIC, J. Biol. Inorg. Chem., 2012, 17, 1269-1281.

27 M. E. Pandelia, P. Infossi, M. Stein, M. T. Giudici-Orticoni and W. Lubitz, Chem. Commun., 2012, 48, 823-825.

28 Y. Rippers, M. Horch, P. Hildebrandt, I. Zebger and M. A. Mroginski, ChemPhysChem, 2012, 13, 3852-3856. 
29 T. Krämer, M. Kampa, W. Lubitz, M. van Gastel and F. Neese, ChemBioChem, 2013, 14, 1898-1905.

30 H. Ogata, K. Nishikawa and W. Lubitz, Nature, 2015, 520, 571-574.

31 C. P. Wang, R. Franco, J. J. Moura, I. Moura and E. P. Day, J. Biol. Chem., 1992, 267, 7378-7380.

32 F. Dole, A. Fournel, V. Magro, E. C. Hatchikian, P. Bertrand and B. Guigliarelli, Biochemistry, 1997, 36, 7847-7854.

33 H. Wang, C. Y. Ralston, D. S. Patil, R. M. Jones, W. Gu, M. Verhagen, M. Adams, P. Ge, C. Riordan, C. A. Marganian, P. Mascharak, J. Kovacs, C. G. Miller, T. J. Collins, S. Brooker, P. D. Croucher, K. Wang, E. I. Stiefel and S. P. Cramer, J. Am. Chem. Soc., 2000, 122, 10544-10552.

34 P. E. M. Siegbahn, J. W. Tye and M. B. Hall, Chem. Rev., 2007, 107, 4414-4435.

35 M. G. Delcey, K. Pierloot, Q. M. Phung, S. Vancoillie, R. Lindh and U. Ryde, Phys. Chem. Chem. Phys., 2014, 16, 7927-7938.

36 P. E. M. Siegbahn, Adv. Inorg. Chem., 2004, 56, 101-125.

37 S. Qiu, L. M. Azofra, D. R. MacFarlane and C. Sun, ACS Catal., 2016, in revision.

38 J. P. Perdew, Phys. Rev. B: Condens. Matter Mater. Phys., 1986, 33, 8822-8824.

39 A. D. Becke, Phys. Rev. A: At., Mol., Opt. Phys., 1988, 38, 3098-3100.

40 M. Svensson, S. Humbel, R. D. J. Froese, T. Matsubara, S. Sieber and K. Morokuma, J. Phys. Chem., 1996, 100, 19357-19363.

41 F. Weigend and R. Ahlrichs, Phys. Chem. Chem. Phys., 2005, 7, 3297-3305.

42 K. N. Kudin, G. E. Scuseria and E. Cancès, J. Chem. Phys., 2002, 116, 8255-8261.

43 C. Peng, P. Y. Ayala, H. B. Schlegel and M. J. Frisch, J. Comput. Chem., 1996, 17, 49-56.

44 C. Gonzalez and H. B. Schlegel, J. Phys. Chem., 1990, 94, 5523-5527.

45 M. J. Frisch, G. W. Trucks, H. B. Schlegel, G. E. Scuseria, M. A. Robb, J. R. Cheeseman, G. Scalmani, V. Barone, B. Mennucci, G. A. Petersson, H. Nakatsuji, M. Caricato,
X. Li, H. P. Hratchian, A. F. Izmaylov, J. Bloino, G. Zheng, J. L. Sonnenberg, M. Hada, M. Ehara, K. Toyota, R. Fukuda, J. Hasegawa, M. Ishida, T. Nakajima, Y. Honda, O. Kitao, H. Nakai, T. Vreven, J. A. Montgomery Jr., J. E. Peralta, F. Ogliaro, M. Bearpark, J. J. Heyd, E. Brothers, K. N. Kudin, V. N. Staroverov, R. Kobayashi, J. Normand, K. Raghavachari, A. Rendell, J. C. Burant, S. S. Iyengar, J. Tomasi, M. Cossi, N. Rega, N. J. Millam, M. Klene, J. E. Knox, J. B. Cross, V. Bakken, C. Adamo, J. Jaramillo, R. Gomperts, R. E. Stratmann, O. Yazyev, A. J. Austin, R. Cammi, C. Pomelli, J. W. Ochterski, R. L. Martin, K. Morokuma, V. G. Zakrzewski, G. A. Voth, P. Salvador, J. J. Dannenberg, S. Dapprich, A. D. Daniels, Ö. Farkas, J. B. Foresman, J. V. Ortiz, J. Cioslowski and D. J. Fox, Gaussian09 (revision D.01), Gaussian, Inc., Wallingford CT, 2009.

46 I. Alkorta, J. Elguero and C. FocesFoces, Chem. Commun., 1996, 1633-1634.

47 Y. Higuchi, H. Ogata, K. Miki, N. Yasuoka and T. Yagi, Structure, 1999, 7, 549-556.

48 F. Weinhold and C. R. Landis, Valency and Bonding. A Natural Bond Orbital Donor-Aceptor Perspective, Cambridge Press, Cambridge, UK, 2005.

49 E. D. Glendening, J. K. Badenhoop, A. E. Reed, J. E. Carpenter, J. A. Bohmann, C. M. Morales, C. R. Landis and F. Weinhold, NBO6.0, Theoretical Chemistry Institute, University of Wisconsin, Madison, USA, 2013.

50 P. Geerlings, F. De Proft and W. Langenaeker, Chem. Rev., 2003, 103, 1793-1874.

51 K. Fukui, Acc. Chem. Res., 1981, 14, 363-368.

52 A. Toro-Labbé, S. Gutiérrez-Oliva, J. S. Murray and P. Politzer, Mol. Phys., 2007, 105, 2619-2625.

53 See some references concerning classical reaction force profiles: L. M. Azofra, I. Alkorta, J. Elguero and A. ToroLabbé, J. Phys. Chem. A, 2012, 116, 8250-8259; L. M. Azofra, I. Alkorta, A. Toro-Labbé and J. Elguero, Phys. Chem. Chem. Phys., 2013, 15, 14026-14036.

54 D. E. Ortega, S. Gutiérrez-Oliva, D. J. Tantillo and A. ToroLabbé, Phys. Chem. Chem. Phys., 2015, 17, 9771-9779.

55 T. Koopmans, Physica, 1934, 1, 104-113. 